ANUARIO DE Estudios MEdIEVALES 45/1, enero-junio de 2015, pp. 185-194

ISSN 0066-5061

doi:10.3989/aem.2015.45.1.06

\title{
LLENGUATGE JURÍDIC I LLENGUATGE POÈTIC: LES GOSADIES DEL COMTE-BISBE MIRÓ BONFILL
}

\author{
LEGAL LANGUAGE AND POETIC LANGUAGE: \\ THE AUDACITIES OF THE COUNT-BISHOP MIRÓ BONFILL
}

Pere J. Quetglas

IRCVM - Universitat de Barcelona

\begin{abstract}
Resum: En aquest treball s'estudia l'originalitat poètica del comte de Besalú i Bisbe de Girona, Miró Bonfill (segle $\mathrm{X}$ ), en un dels documents que hom li atribueix: l'acta de confirmació de la dotació de l'església de Sant Pere de Besalú. L'anàlisi dels 27 versos identificats en aquest document posen en relleu una clara dependència de Miró Bonfill d'altres poetes com Paulí d'Aquileia o Venanci Fortunat, però també l'existència de relacions amb altres obres, anteriors, contemporànies $\mathrm{i}$ posteriors, circumstància que obre nous interrogants sobre les relacions literàries de Catalunya amb Europa al segle X.
\end{abstract}

Paraules clau: llatí medieval; poesia llatina medieval; literatura llatina a Catalunya; Miró Bonfill.

\begin{abstract}
This paper addresses the poetic originality of Miró Bonfill, count of Besalú and bishop of Girona (tenth century), in one of the documents attributed to him: the provision certificate of the church of Sant Pere de Besalú. The analysis of the 27 verses contained in this document shows an evident dependence on poets like Paulinus of Aquileia and Venantius Fortunatus, but it also allows to trace connections with other contemporary and later works. This fact poses new questions on the literary links between Catalonia and Europe in the tenth century.
\end{abstract}

Keywords: medieval Latin; medieval Latin poetry; Latin literature in Catalonia; Miró Bonfill.

1. Llenguatge jurídic i llenguatge poètic.- 2. Miró Bonfill i la poesia.-3. Bibliografia citada. 


\section{LLENGUATGE JURÍDIC I LLENGUATGE POÈTIC}

En el marc dels estudis que duim a terme en el si del grup d'investigació del Glossarium Mediae Latinitatis Cataloniae $(G M L C)^{1}$, ja fa un temps que vàrem endegar una línia de recerca de caràcter més literari que lexicogràfic, tot i que també relacionada amb el lèxic; aquesta línia tenia i té com a objectiu la recerca i detecció de reminiscències literàries, especialment poètiques, en els documents llatins redactats a Catalunya a l'alta edat mitjana. El resultat d'aquesta recerca ha estat prou fructífer i ens ha permès arribar a la revalorització literària de certs escrivans o a la revisió de les qualitats poètiques que hom els atribuïa. I com a resultat de tot plegat s'han pogut incloure en el cànon dels nostres escriptors medievals figures com Ermengol Bernat d'Urgell ${ }^{2}$ o s'ha pogut matisar i calibrar millor l'abast de les suposades capacitats poètiques del comte-bisbe Miró Bonfill ${ }^{3}$. Importa especialment destacar aquí el marc dins del qual es duen a terme aquestes investigacions. El material objecte d'estudi són documents de caire jurídic i, molt sovint, del que avui en dia anomenaríem de caire notarial; és a dir, contractes de compra-venda, donacions, plets, testaments, judicis, etc. Aquests documents, precisament pel seu vessant jurídic i per la voluntat d'exactitud que hom els suposa, no són el lloc més adient per exercitar-hi vel·leïtats literàries o poètiques, ja que la literatura i la poesia, afectades com estan per la utilització de trops i/o metàfores, podrien induir fàcilment a l'error, a la confusió i a l'ambigüitat. Ara bé, una cosa és la lògica i una altra, la realitat.

No fa massa anys, el 2011, el jutge Álvaro Gaspar Pardo de Andrade va haver d'afrontar una investigació de la Comisión Disciplinaria del Consejo General del Poder Judicial per haver redactat una sentència en vers. El CGPJ va decidir en darrera instància arxivar la causa, tot i no compartir la forma en què estava redactada la sentència. No era la primera vegada que aquest jutge-poeta recorria a la poesia a l'hora de redactar una sentència, ja que l'any 1999 havia redactat una sentència d'un cas de divorci tot emprant els termes següents:

${ }^{1}$ Grup de recerca consolidat reconegut per la Generalitat de Catalunya (2014 SGR 929). En el sí del grup es desenvolupen així mateix els projectes de redacció i d'informatització del Glossarium Mediae Latinitatis Cataloniae (FFI2012-38077-C02-01 i FFI2012-38077-C02-02) subvencionats per la Dirección General de Investigación Científica y Técnica del Ministerio de Economía y Competitividad del Gobierno de España dins del subprograma de "Proyectos de Investigación Fundamental no Orientada". Així mateix, el GMLC forma part dels programes de recerca de l'Institut d'Estudis Catalans (PUAI1985-QUETGLAS).

${ }^{2}$ Vegeu Quetglas 1992, 2005.

${ }^{3}$ Quetglas 2013. 


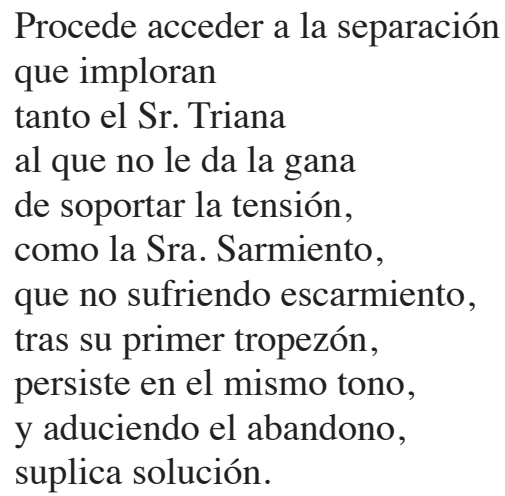

Sembla que en aquest darrer cas hi ha haver una sanció econòmica per al jutge, qui, d'altra banda, no se n'estava de defensar públicament la seva dèria poètica adduint que si el fallo es bello además de justo, el derecho sale ganando ${ }^{4}$.

Aquesta forma d'actuar no és un cas aïllat i únic, sinó que podem trobar comportaments paral·lels en sentències de jutges americans, en informes de policies brasilers o en l'obsessió d'un professor nordamericà per intitular els seus articles amb textos de les cançons de Bob Dylan ${ }^{5}$.

\section{MIRÓ BONFILL I LA POESIA}

Considerant aquestes premisses no ens pot estranyar gens ni mica que a l'època medieval hi hagués també jutges, notaris o escrivans tocats per una afecció poètica semblant. I encara menys en el cas de Miró Bonfill, atès que l'ús de lèxic i formes poètiques servia per donar llustre als documents, cosa especialment indicada quan els firmants o redactors pertanyien a les nissagues governants. Era una manera més de marcar diferències. En un treball anterior $^{6}$ ja ens ocupàrem d'aquesta dèria de Miró Bonfill, comte de Besalú (965-984) i bisbe de Girona (971-984), exemplificada en l'acta de consagració de l'església de Cuixà (any 974). Allà posàvem de manifest, en contra del que era doctrina communis, que Miró Bonfill, tot i recórrer en els seus escrits a la poesia, no ho feia com a poeta creador, sinó reutilitzant textos d'altres poetes. Seguint, doncs, en aquesta mateixa línia de treball, ens ocuparem aquí d'un

\footnotetext{
${ }^{4}$ Vegeu Hernández 2011.

${ }^{5}$ Vegeu Anaya Huertas 2012.

${ }^{6}$ Quetglas 2013.
} 
altre dels documents redactats per Miró Bonfill, l'acta de confirmació de la dotació de Sant Pere de Besalú, datada el 2 de juliol del 978. De la qüestió se n'han ocupat amb anterioritat Anscari M. Mundó ${ }^{\text {i Josep M. Salrach }}{ }^{8}$. El document es divideix en dues parts molt clarament definides: el preàmbul i la part pròpiament dotacional. D'aquesta última no ens n'ocuparem aquí, sinó que ens centrarem exclusivament en el preàmbul, que és el lloc que permet una llibertat més gran. En l'edició de Junyent-Mundóg i, després, en l'edició de Catalunya Carolíngia ${ }^{10}$, aquest preàmbul ja es presenta de forma diferenciada, tot distingint unes parts en prosa d'altres en vers. Reproduïm tot seguit l'edició de Catalunya Carolíngia, en la qual hem numerat separadament les parts versificades (les indicam amb números romans entre claudàtors a l'esquerra del text) a fi de facilitar les referències. Cal tenir en compte, així mateix, que l'edició inclou entre parèntesis quadrats la part del text que s'ha completat a partir de l'edició de J. Villanueva ${ }^{11}$ :

Si famulorum meritis debite compellimur compensare lucra mercedis, quanto iam copiosius pro remediis animarum divinis cultibus terrena debemus impendere et impensa per scripturas legaliter confectas decentissime adfirmare. Quapropter ego Miro, nutu Dei sancte Ierundensis ecclesie perhumilis episcopus, unacum quonibencia meorum caterve clericorum laicorumve fidelium elegi quendam ecclesiolam a dominatu homnium ecclesiarum libera,

[I] quam venerandus habet propriam beatissimus Petrus apostolorum princebs edem, nomine sub cuius sanctificata nitet,

sita videlicet iuxta opidum

[II] quem holim Bisuldunem voluit [vocitare] vetustas, sed [cuius meritum scimus] percurrere mundum; uius ubique iure surgere templa decet.

Et quemadmodum ab ipso Domino Iesu Christo didicimus:

[III] Quecumque vinclis super terra strincxerit erit ligatum super celos fortiter, et quod resolvit in terris arbitrio erit solutum supra celis [radios];

5 in fine mundi iudex erit aevi.

\footnotetext{
${ }^{7}$ Junyent 1992, pp. 4-6.

${ }^{8}$ Salrach 1989.

${ }^{9}$ Junyent 1992, pp. 4-6.

${ }^{10}$ Sobrequés, Riera, Rovira 2003, doc. 448, pp. 400-406.

${ }^{11}$ Villanueva 1850, vol. XV-25, pp. 254-262. Hem utilitzat també aquesta edició per esmenar alguns errors de detall.
} 
Ob tanti igitur patroni amorem [pro remediis] animarum meorum parentum meaeque, et super omnia pro remedio anime domni Seniofredi, comitis hac fratris mei, qui michi copiosa bona, dum vixit, contulit,

[IV] quem Deus omnipotens ad illut perducat regnum, [quod] primus homo perdidit gustando proibito pomo; possit et ad lignum vite [perducere gustum, ut] valeat eternos semper carpere fructus,

5 ex quibus eternum ducat sine mensibus annum et sine sole diem, lucem sine nocte peremnem in patria, paradisse, tua quam rite beatus dilexit hic comes, vita dum fuit in ista.

Pro remedio igitur anime predicti comitis et pro salute [tam animarum quam corporum meorum] fidelium in ac terra degentium qui illo cenobio aliquo prestiterint benefitium, seu pro statu celsitudinis sive salute domni [Olibani comitis] sueque coniungis suorumque filiorum, quorum [vitas

[V] omnipotens Deus multis protelare] dignetur temporibus ut vivant Deo [felices longo feliciter evo; et post] huius vite [excursum celeste] mereantur perfruere regnum,

5 in quo detineant magnarum gaudia rerum; [gaudia que] nullus [vivens decernit] ocellus, nec aliquis vigili poterit comprendere corde; quod Deus in terris voluit [promittere sanctis], et residens celos voluit [concedere iustis].

De les cinc sèries de versos, una, la tercera, no té cap misteri a partir del moment en què A. M. Mundó identificà els cinc versos que conté com a pertanyents o molt directament inspirats en un himne de Paulí d'Aquileia ${ }^{12}$ (ca. 735-802) dedicat al apòstols Pere i Pau, circumstància que s'adiu plenament amb la seva utilització en la dotació d'un temple situat sota l'advocació de Sant Pere ${ }^{13}$. La coincidència amb els versos de Paulí és gairebé total, llevat de uns poc mots que posem en cursiva, la qual cosa ens pot induir a pensar de forma justificada en una utilització memorística del text de Paulí:

5 Quodcumque vinclis super terram strincxerit

Erit in astris religatum fortiter:

Et quod resolvit in terris arbitrio,

Erit solutum super caeli radium.

In fine mundi Iudex erit seculi.

${ }^{12}$ Autor del segle VIII, lligat a la cort carolíngia i especialment conegut per la seva participació en la polèmica antiadopcionista.

${ }^{13}$ Paulinus Aquileiensis 1964, Hymnus de Petro et Paulo 5, p. 137. 
Ara bé, això són cinc versos sobre un total de 27 ; i què passa amb la resta? En primer lloc, cal fer notar una vegada més que no anem a la recerca de coincidències escadusseres que poden obeir a influències múltiples i gairebé sempre impossibles de determinar. Així, que el sintagma protelare dignetur temporibus [V 1-2] el trobem de forma idèntica al manual de Dhuoda $^{14}$, no deixa de ser segurament una simple casualitat. En tot cas, l'hem d'indicar, però no ens atrevim a passar d'aquí i extreure'n més conclusions. I el mateix passa amb la frase ut vivant Deo felices longo feliciter evo $[\mathrm{V}, 2]$ que té una notable similitud amb el vers 19 del cant epitalàmic dedicat a Leodegúndia, la filla del rei Ordoño I d'Astúries (850-866): ut vigeat longo feliciter $\mathrm{evo}^{15}$. Tot i que en aquest darrer cas les relacions s'amplien a partir del moment que a l'epitafi d'aquest mateix rei apareix un vers clarament inspirat en Eugeni de Toledo (Carmina XXVIII, 8) i que també fou utilitzat per Miró Bonfill a l'acta de consagració de l'església de Cuixà ${ }^{16}$. Menys feble és la relació que podem establir amb un text de les fórmules merovíngies editat per Karl Zeumer ${ }^{17}$, encara que tampoc no puguem qualificar-la de definitiva, ja que tot fa pensar en un origen paral-lel i no gaire llunyà, però sí diferent:

\title{
Formulae Merowingici et Karolini Aevi e codice parisiensi Lat. 4841 V
}

\begin{abstract}
Deus omnipotens almitatem vestram longe ob edificationem aecclesie vestre et multorum solatia protelare dignetur atque post excursum labentis vitae cum multorum operum fructu ad aeternae gloriae triumpho perducat, ut, cum quibus hic mente et conversatione fuistis semper, cum eis aeternaliter gaudere regnareque mereamini. Amen.
\end{abstract}

Molta més entitat té la influència de Venanci Fortunat, poeta del segle VI molt lligat a la cort merovíngia, autor de poemes laudatoris a diversos sants o commemoratius de la fundació de moltes esglésies ${ }^{18}$. La temàtica de les seves composicions el convertia en una font perfecta per a Miró Bonfill, qui, al cap i a la fi, no pretenia fer res de diferent. Així, els dos versos de la secció [I], tot i que el primer no sembli pròpiament un vers, es corresponen

\footnotetext{
${ }^{14}$ Dhuoda 1991, vol. X, 6, pp. 4-5.

${ }^{15}$ Anglès 1970, pp. 42-48.

${ }^{16}$ Vegeu Quetglas 2013, pp. 423-425.

${ }^{17}$ Zeumer 1886 , p. 531.

${ }^{18}$ Sobre la utilització de Venanci Fortunat per part de Miró Bonfill a l'acta de consagració de l'església de Cuixà, vegeu Quetglas 2013.
} 
exactament amb el dístic elegíac que formen dos versos del poema XI del llibre I dels Carmina ${ }^{19}$ :

XI. De basilica domni Dionisii (vv. 11-12)

quam uenerandus habet propriam Dionisius aedem, nomine sub cuius santificata nitet.

Com es pot comprovar fàcilment, la pèrdua de l'aparença poètica del vers $[I, 1]$ respon a la necessitat de l'adaptador de substituir el subjecte Dionisius per un nou actor: beatissimus Petrus apostolorum princebs.

D'altra banda, els tres versos de la secció [II] procedeixen de forma manifesta dels carmina de Venanci Fortunat:

quem holim Bisuldunem voluit vocitare vetustas, sed cuius meritum scimus percurrere mundum; uius ubique iure surgere templa decet.

En concret, del poema 9 del llibre primer:

\section{Item de Basilica Sancti Vincenti Vernemetis}

Cultoris Domini toto sonus exiit orbe nec locus est ubi se gloria celsa neget, sed cuius meritum scimus percurrere mundum, huius ubique uiri surgere templa decet.

5 Ecce beata nitent Vincenti culmina summi, munere martyrii qui colit astra poli, promptus amore pio quae papa Leontius olim condidit eximio consolidata loco. Nomine Vernemetis voluit vocitare vetustas, quod quasi fanum ingens gallica lingua refert.

És clar que en alterar Miró Bonfill l'ordenació original dels versos, es perd la unitat compositiva en dístics elegíacs. Diguem, així mateix, de passada que la frase voluit vocitare vetustas, amb un al-literació ben expressiva, era un recurs corrent, que Venanci Fortunat usa en altres ocasions i al qual ja havia recorregut anteriorment Miró Bonfill a l'acta de consagració de l'església de Cuixà, a la qual ens acabam de referir ${ }^{20}$.

\footnotetext{
${ }^{19}$ Fortunat 2002, vol. I-1, XI.

${ }^{20}$ Quetglas 2013, p. 423.
} 
De la secció [V], més enllà del que ja hem assenyalat abans, és poc més el que podem dir. M.C. Díaz y Díaz ${ }^{21}$, tot i ocupar-se un poc de passada d'aquest document, va posar en relleu alguns aspectes força interessants, ja intuint per on devien anar els trets. En primer lloc, establia com a font d'inspiració dels quatre últims versos la primera carta als Corintis de Sant Pau: sicut scriptum est quod oculus non uidit nec auris audiuit nec in cor hominis ascendit quae praeparauit deus his qui diligunt illum $(1$ Cor 2,9). En segon lloc, parlant de $[\mathrm{V}, 2]$ diu:

En cuanto al que presento, de acuerdo con la edición, como segundo verso ([V, 2]), hay que tener en cuenta que parece resultado de una serie de operaciones, en que se funden cosas distintas, y aparecen algunas inclusiones indebidas: es claro que temporibus ut no puede formar parte del hexámetro propiamente dicho, en el que además sobra, de acuerdo con el sentido, deo, quizás inducido aquí por la secuencia ut uiuant deo. Pero el conjunto no puede decirse fruto de la casualidad, sino resultado de un esfuerzo muy deliberado, en que quizá se aprovecharon retazos de otros poemas.

Amb tot, hom es queda amb la sensació que encara podrem trobar en el futur algun poema que ens il-lumini sobre la procedència d'aquests versos. Arribem així al punt per a nosaltres més enigmàtic, el de la secció [IV]. És evident que els hexàmetres d'aquesta secció tenen un parentiu evident amb la composició CXXXI de la recopilació de Hermann Hagen ${ }^{22}$.

\section{CXXXI \\ Versus de monachis}

20 Quod potuit gaudens gustato perdere pomo, Possit et ad lignum uitae perducere gustum, Eius ut aeternos ualeat decerpere fructus, Ex quibus aeternum ducat sine mensibus annum, Et sine sole diem, lucem sine nocte perennem.

25 Unus namque dies aeternum conficit annum, In patria, paradise, tua, quam rite beatus

Diligit hic monachus, patria dum degit in ista.

Tret d'alguns canvis en la disposició dels versos, en l'omissió d'algun altre o en l'adaptació de l'últim vers on, per raons òbvies, en lloc de monachus tenim comes, la semblança és palesa. Ara bé, hi ha un petit in-

\footnotetext{
${ }^{21}$ Díaz 1997, pp. 292-293.

${ }^{22}$ Hagenus 1877, poema CXXXI: Versus de monachis, pp. 205-206.
} 
convenient; resulta que els Versus de monachis estan datats entre el segle XII i el segle XIII, i són, per tant, molt posteriors als versos de Miró Bonfill, del segle X; de manera que, parlant amb propietat, hauríem d'expressar-nos canviant l'ordre: és a dir, que en lloc de comes, trobem monachus. Clar que això ens podria dur a concloure que els Versus de monachis són deutors de la poesia de Miró Bonfill i això, evidentment no lliga ni amb el que sembla ser la forma d'actuar del nostre erudit ni tampoc amb la posició perifèrica i residual que tenia el monestir de Ripoll respecte a Europa, per molt de greu que ens sàpiga. Lamentablement, encara no hem sabut trobar la peça intermèdia que ens ha de permetre relacionar els dos textos de una manera natural i no forçada.

Mentre tant, totes les evidències són molt insistents en presentar-nos Miró Bonfill com un erudit que s'havia especialitzat en adaptar versos d'altri a l'hora de confegir els seus textos i sempre amb la voluntat de donar als documents que redactava el màxim relleu possible; amb d'altres paraules, ara per ara no passa de ser un bon poeta centonari.

\section{BIBLIOGRAFIA CITADA}

Anaya Huertas, Alejandro (2012), Jueces poetas, "Nexos. El juego de la suprema corte" noviembre 1, http://eljuegodelacorte.nexos.com. $\mathrm{mx} / \mathrm{p}=2187$ [consulta: $31 / 07 / 2014$ ].

Anglès, Higini (1970), Historia de la música medieval en Navarra, Navarra, Institución Príncipe de Viana.

Dhuoda (1991), Manuel pour mon fils, Introduction, texte critique, ed. Pierre Riché, traducció per Bernard de Vregille i Claude Mondésert, París, Éditions du Cerf (2a edició).

Díaz y Díaz, Manuel Cecilio (1997), La cultura medieval y los mecanismos de producción literaria, en VII Semana de Estudios Medievales: Nájera, 29 de julio al 2 de agosto de 1996, Logroño, Instituto de Estudios Riojanos, pp. 281-295.

Fortunat, Venance (2002), Poèmes, T. I, livres I-IV. Texte établi et traduit par Marc Reydellet, París, Les Belles Lettres.

Hagenus, Hermannus (1877), Carmina Medii Aevii maximam partem inedita, ex bibliothecis Helveticis collecta, Berna (Torí, Bottega d'Erasmo, 1971, fasc.).

Hernández, José Antonio (2011), El poder judicial archiva el caso del juez poeta, "El País", 26 de octubre.

http://politica.elpais.com/politica/2011/10/25/actualidad/ 1319570678_096081.html [consulta: 31/07/2014].

ANUARIO DE Estudios MedieVAles, 45/1, enero-junio 2015, pp. 185-194

ISSN 0066-5061, doi:10.3989/aem.2015.45.1.06 
Junyent i Subirà, Eduard (1992), Diplomatari i escrits de l'abat i bisbe Oliba, a cura d'Anscari M. Mundó, Barcelona, Institut d'Estudis Catalans.

Paulinus Aquileiensis (1964), Carmina, V, dins Poetae Latini Aevi Carolini I, Monumenta Germaniae Historica V/5, recensuit Ernestus Duemmler, Berlín, Weidmann, pp. 123-148 (2a edició).

Quetglas, Pere J. (1992), Nota sobre la cultura dels escrivans medievals a Catalunya, dins Humanitas in honorem Antonio Fontán, Madrid, Gredos, pp. 313-317.

Quetglas, Pere J. (2005), La Vita Adalbertini de Ermengol Bernat d'Urgell, "Euphrosyne" 30, pp. 279-287.

Quetglas, Pere J. (2013), Las cualidades poéticas de Miró Bonfill, dins Muñoz, María José; Cañizares, Patricia; Martín, Cristina (eds.), La compilación del saber en la edad media, Porto, FIDEM, pp. 417-427.

Salrach, Josep Maria (1989), El comte-bisbe Miró Bonfill i la fundació i dotació de Sant Pere de Besalú, "Annals del Patronat d'Estudis Històrics d'Olot i Comarca", pp. 9-44.

Sobrequés i Vidal, Santiago; Riera, Sebastià; Rovira, Manuel (2003), Els comtats de Girona, Besalú, Empúries i Peralada. Catalunya Carolíngia, vol. V/2, revisat i completat per Ramon Ordeig i Mata, Barcelona, Institut d'Estudis Catalans.

Villanueva, Jaime (1850), Viage literario a las iglesias de España, vol. XV, Madrid, Impremta Real.

Zeumer, Karolus (1886), Formulae merowingici et karolini aevi. Accedunt ordines iudiciorum Dei. Monumenta Germaniae Historica. Legum. Sectio V. Formulae, Hannover, Hahniani.

Fecha de recepción del artículo: agosto 2014

Fecha de aceptación y versión final: febrero 2015 